\title{
Newly Qualified Doctors' Views of Medical School Training and Its Adequacy in Making Them "Fit for Purpose" as First Year Doctors
}

\author{
Peter Hayes \\ Discipline of G.P. and Primary Care, N.U.I., Galway, Ireland \\ Email: peter.hayes@nuigalway.ie
}

How to cite this paper: Hayes, P. (2016) Newly Qualified Doctors' Views of Medical School Training and Its Adequacy in Making Them "Fit for Purpose" as First Year Doctors. Open Access Library Journal, 3: e2799. http://dx.doi.org/10.4236/oalib.1102799

Received: August 16, 2016

Accepted: September 18, 2016

Published: September 21, 2016

Copyright (C) 2016 by author and Open Access Library Inc.

This work is licensed under the Creative Commons Attribution International License (CC BY 4.0).

http://creativecommons.org/licenses/by/4.0/

\section{(c) (i) Open Access}

\begin{abstract}
Aim: To assess whether the medical graduates from one medical school felt "fit for purpose" to work as intern doctors in the Health Service in Ireland. In the early nineties documents like "Tomorrow's Doctors" emphasised the direction and change that undergraduate medical training had to take. It stated that "students must be properly prepared for their first day as Pre-Registration House Officer". There are current arguments that junior doctors are not fully prepared for working life when they finish university. This study aims to analyse this perceived truth. Methods. I employed use of semi-structured interviews with a purposive sample of medical school's qualified interns. A grounded theory thematic analysis approach was used. Results. The interviews confirmed the participants' sense of being ill-prepared for the complexities of being a doctor. Issues such as managing professional relationships, navigating hospital politics, building support networks, knowing when to seek help and dealing with ethically challenging situations were all highlighted. Conclusions. The study has established that the medical school in which the study was situated is teaching its graduates to an acceptable standard with regard to their medical knowledge base, communication skill abilities and the basic tenets of history taking and examination, but it needs to prepare graduates in a more concrete way for working in complex multiprofessional clinical environments and for participating effectively in the context of acute medical emergencies. It is arguable that all medical schools should follow up their graduates to assess how well the medical school curriculum has prepared their graduates for practice.
\end{abstract}

\section{Subject Areas}

Education

\section{Keywords}

Fitness for Purpose, Transitions to the Workplace, Interns, Medical Graduates 


\section{Introduction/Aims}

The obvious aim of a medical school is to produce graduates who can work successfully as doctors, although there seems to be no clear consensus on how to train doctors [1]. In the early nineties, it was generally accepted that medical training had to improve. Documents like "Tomorrow's Doctors" emphasised the direction and change that undergraduate medical training had to take. It stated that "students must be properly prepared for their first day as Pre-Registration House Officer" [2]. These changes in the nineties made medical schools look at curricular change in a new light. Medical training had to become more focussed on outcomes and competences for the "working doctor", and less knowledge based and self-directed.

If doctors arrive on the wards unprepared for work, there are clear and obvious threats towards patient safety. Is enough dialogue, in a medical context, taking place between universities and National Health Service Executives? Are healthy employers clear to universities about the type of graduate they need for the workforce?

Medical interns are expected to be able to perform tasks and manage patients from the minute they start work. Are they fit for this purpose?

\section{Methods}

\subsection{Interviews/Sampling of Interviewees}

Further details can be found in the "Interview Details" $(\mathrm{N}=10)$ regarding gender, age and postgraduate status in Table A1. Four interns were recruited via text message sent to the intern group. Four further interns were purposefully recruited in order to avoid bias. These included a further two female interns and an intern doctor who was already a graduate upon commencement of medical school. Two further interviewees consented via a "snowball effect" and hearing about the project from friends. Table A2 shows the semi-structured interview guide.

\subsection{Data Analysis and Quality}

I employed thematic analysis using some of essential tenets of a grounded theory approach [3]. These included constant comparison and iteration between emergent findings and subsequent interview schedules. There was initially a process of pre-coding, descriptive coding and interpretive coding, and then finally the formation of overarching themes [4]. There were quality checks made at each step. This included co-coding, respondent feedback (verbal through informal chatting), and making a clear audit trial available throughout. A reflexivity journal was maintained during the entire process of analysis.

\section{Results}

A list of overarching themes and quote examples can be found in Table A3.

\subsection{Overarching Theme 1.0: Real World Issues for the Student Transitioning to Doctor}

$\underline{\text { Procedural and patient consent dilemmas }}$ 
“When I started one of the surgical rotations, I didn't know, I didn't know what I am to do here, and I am meant to be telling a patient what is going on."

(Interview 4, male, traditional entry, early twenties)

The interns felt that the ethical teaching received in university does not reflect the actual practice of taking consent for procedures from patients on wards. Interns frequently attain from patients consent for procedures that more senior doctors are performing. They are all too often not adequately informed about the procedures. Interns are especially vulnerable to this when working on specialists teams, and the procedures are just simply not known or understood.

"I do also think there's an issue with elderly people and intellectual disabled people, with who signs the form. Oftentimes $P$ ve brought it up on rounds, being like, "If this is any issue, this consent form will not legally stand." And senior members of the team don't really care about that. They' re just like, "Just sign the form, do you know, and get it done with."

(Interview 8, female, traditional entry, early twenties)

There is also often a veiled assertion within the hierarchy of medical teams that the interns need to do this "consent procedure" with patients quietly and without asking too many questions or obstructing the flow of patients to the operating theatre. There can also be significant time pressure issues in preparing patients for the operating theatre with multiple consent signings to do and a very short space of allotted time to do it in. Consultant discussions regarding the procedure with the patient in an out patients setting but this may have been many months previous to the surgery day and anaesthetic or rare complications are not regularly discussed.

Competence in resuscitation

"I think I did 20 calls or something I think I only had five arrests. When you go to them I don't think much is expected of you. You either try to get a line or try to get an $A B G$ or do the compressions like; no one will really be kind of counting too much on you. That's what I found anyway."

(Interview 5, male, traditional entry, early twenties)

There are resuscitation events frequently but the amount of these often depends on the local hospital policy. In some hospitals there are strict protocols on consultants letting ward staff know who is for resuscitation and who is not. These decisions are made at senior levels taking into account the seriousness of the illness and the potential for recovery of the patient. Interns seem not to be vital at these resuscitation events but contribute very basically to the resuscitation drill when present. The descriptions of leadership at these events are very variable and the resuscitations do not always go according to plan. A good resuscitation event can be a great memory for intern doctors.

Ethics for the frontline as a new doctor

"We didn't spend more than a few minutes on him (Resuscitation on a patient) and he (Registrar) just decided very quickly and very suddenly (to stop the resuscitation) and it was sort of ... I was a bit surprised but then I thought that was just me, but you know, my anaesthetic colleagues and nursing colleagues from the medical side, they 
were all a bit surprised at it initially."

(Interview 7, male, traditional entry, early twenties)

The making of complex clinical care decision, demands a solid ethical framework. Care based decisions are made daily on wards by more senior doctors, but those in the intern group do not always understand these fully. There is not any clear framework within the medical system for "point of care" ethical decisions. In the instance quoted above, even though many members of the resuscitation team above questioned a care decision, nobody felt strong enough to demand a reassessment of the decision. There were also many instances interns spoke about regarding "not for necessitation" labels attached to patients. One intern spoke about a drill where a patient who had had a cardiac arrest, and was too ill to recover their health, but because a "not for resuscitation order" was still unsigned; the entire team went through the motions of a resuscitation drill for show. There was a full understanding that the drill was not to succeed at the outset.

Patient safety and preparedness for work

"There is a couple of people I suppose with us that kind of did some kind of crazy things at the start which is purely because they were, you know, I don't even think it was over confidence it's more just kind of ... managing sort of like people like who are given heaps of fluids and have CCF and putting them putting them into heart failure."

(Interview 5, male, traditional entry, early twenties)

There are still issues expressed around patient safety and the skills that interns initially have in managing sick patient on hospital wards. The overall feeling however is that the patient group is largely safe. Most interns have the approach that they should not manage sick patients alone until they are more settled and competent within the job. For the most part, those more senior are available to call or help, but errors still occur. There were no serious critical incidents disclosed to me.

Vein cannulation skills at the start of the internship are initially very weak. Patients invariably suffer through multiple cannulation failure attempts. This can also have a knock on effect as patients may not have cannulae for their intravenous medication doses and help from those more senior, whilst forthcoming, may have a significant waiting time. In the first few weeks, the on call pressures from not getting blood samples and vein cannulation tasks completed can be immense for interns.

"On call", the opinions of other interns and paramedical staff can be wrong or completely mis-informed and this can lead to patients safety issues as a certain patient may not be triaged correctly on the urgency of a review Information is frequently sought and given over the telephone in these instances and perhaps this is a poorly taught communication skill modality.

\subsection{Overarching Theme 2.0: "Ward Life and How It Impacts on Performance"}

Practicalities of ward life

"My typing skills are definitively not up to scratch, It really does input on my output 
at work, to do written discharges and stuff, or they could be on computers. You could spend an extra twenty minutes doing it because of the typing."

(Interview 3, male, traditional entry, early twenties)

Time management is a needed skill for internship. This is most apparent on call where multiple "bleeps" can come simultaneously, and the ability to work off your own steam on task completion takes a while to learn. Time management is felt to be a personality issue and although skills and tricks to maintain efficiency are developed throughout the year, those who feel they are poor managers of time, often remain feeling that way. Those who multi task seem to perform better than those who don't or cannot.

Hospital information technology systems are impossible to access as a student; due to confidentiality fears health service management seem to have. When interns start work, each hospital has a totally different radiology and laboratory or patient discharge computer system. This most certainly adds to the stress upon starting work. Typing skills are mentioned as being a real weakness amongst some interns and this in turn can slow down their job completion rate dramatically.

After Dark (On-Call)

“Well, Im not really sure who's sick or who's not sick and I don't really know what anything means."

(Interview 10, female, traditional entry, early twenties)

There are certain regular on-call situations for which interns feel poorly prepared. We can call these "common calls". They would usually involve things like managing an agitated patient, prescribing certain ward based drugs, prescribing intravenous treatments or doing patient reviews for concerned nursing colleagues. Interns feel that the management for these common calls is learned "at work "rather than having prior experience of this type issue. They would appreciate more training here. There may be slight knowledge deficits here in pharmacology and on the management of these "common calls". All of the interns rate any "live training" they receive on "common calls" as invaluable. Help from seniors can be variable on any particular night depending on how busy the senior is.

Getting the information via phone calls can be tricky. In busy and noisy environments; it can be a challenge to get all the correct and descriptive details on a patient. This ability to prioritise which calls are urgent, which can wait, and which demand attention as late as tomorrow is the largest challenge faced by interns. There is little training for this. To add further difficulty to the mix, interns frequently spend time arguing with paramedical colleagues (nurses), on which patient needs to be seen as a priority.

\subsection{Overarching Theme 3.0: "Professional Relationships and Their Impact on Preparedness for Work"}

Nursing colleagues and how relationships impact on performance

"Students can be coming out at 22 years of age and they are expected to kind of 
command the respect of the kind of the 40 or 50 year old nurse on the wards."

(Interview 2, male, postgraduate entry, late twenties)

Many of the interns certainly felt that the complexity of the work environment was a shock to them. The main professional relationship that interns need to develop is with nursing colleagues. This relationship is complex, mainly because of the ongoing hierarchical systems still at play within the health service; where doctors issue management and pharmaceutical orders and the nurse fulfil these orders whilst being the prime providers of bed-side patient care. Interns are novices when first they enter the ward environment. They are initially very reliant on nurses for help with clinical skill tasks, intravenous drug tasks, medication and patient management tasks and for "sick-patient" prioritisation decisions. The nurses also orientate all new doctors to the ward and indeed the broader hospital. This reliance then fades a little as the new doctor becomes more comfortable within his new role.

"I find that when you' re not as busy, you' re really nice and they' re really nice and it's all very civil. And then when you' re busy or they' re busy, it gets very heated and sometimes, you know."

(Interview 10, female, traditional entry, early twenties)

There seem to be multiple frustrations for interns in their personal dealing with nursing colleagues and this frequently leads to conflict and stress. There is a belief amongst the interns that nursing colleagues can page interns relentlessly to complete tasks or reviews on their own wards and may be oblivious to the business of the hospital or other wards on any particular night. Explanations for prolonged absence from a ward are often refuted and each ward may demand the completion of the tasks on that ward, without due regard to the "job prioritisation" mindset that interns need to adapt. There are suggestions that nursing colleagues may over-play patient ill health in order to get the tasks completed on their own wards.

Medical seniors and their roles

"My reg said to me about two weeks in 'How are you getting on?' and I said 'Well I am a bit less stressed about them (cannulae) now' and he was like 'Don't ever, ever be stressed about them, I will always come and do that unless I am operating' ... but what when nobody is kind of saying 'Don't worry about that, that doesn't matter'."

(Interview 6, female, traditional entry, early twenties)

There are variable levels of support available to interns at work. This seems largely team dependent and surgical teams are generally less supportive as a rule as registrars are often in theatre. The interns as a group though recognise the need to realise their limits. Some interns remarked that the level of support they received when they asked for help was superb and not at all as negative as they expected. This "waiting around" for a senior to help can make the work load on a busy night much larger, especially if the intern needs to repeat this call for help again later. The nervousness about bothering a senior doctor, who clearly does not appreciate calls for help on a busy night and the knowledge that "waiting" for help slows down the job task completion rate, are some of the reasons why interns feel they have not called for help when possibly 
needed. This does not seem to impact on patient safety, as all procedural and more complex ward based tasks were fully supported. It seems to relate more to middle ranking ward based tasks. Examples of these tasks include, getting consent for a procedure that is not known to the intern or perhaps taking out a venous central line system that maybe unknown to the intern.

Interns are expected to carry out low risk tasks like venepuncture and cannulation without supervision on call, as patient safety issues would be deemed low. There is an expectation, rightly or wrongly that all interns are competent to do this, but prior experience may be limited. The senior house officers (second year doctors) are vital in the up skilling of the intern in these tasks.

Skills for acquiring cross-team consults

"Like very commonly, you'd ring somebody, be like, 'Hi, and my name is whatever from the blah, blah, blah team.' And before you even say anything, they' re like, 'Well, who are you on blah, blah, blah's team? Are you the intern, the SHO or the reg?' And that kind of changes the conversation."

(Interview 10, female, traditional entry, early twenties)

Consults are a constant source of stress for interns. A consult is when your own team, after admitting a patient, gets the intern to contact another specialist service within the hospital environment to ask for a bed-side review of the patient. It usually requires the intern calling a senior doctor on another team, who is most likely unknown to them, putting forward a strong verbal case as to why a review is needed and then continuously contacting this senior doctor until they give a consult opinion.

The interns often are unsure what the consults are for, as some supervisors ask for consults on every clinical finding outside of their specialist knowledge area. The consult request can thus be quite "weak" and this makes it even harder for interns to call senior doctors from other teams and "sell" the need for a review. The calling of senior doctors is daunting, as the registrar on the other end of the phone line, will be trying to limit their own workload and may sound austere and temperamental. Many interns avoid these tasks fully because of the fear it induces, and swap tasks with intern colleagues who are happy to do these type calls.

The ability to get the reviewer to come to the bed side requires some inside-knowledge of the workings of hospital system and the correct terminology or communication skills in getting a consult. These fine details are certainly not taught in medical school but passed informally between those more senior and junior.

\subsection{Overarching Theme 4.0: "Skills Deficits in the Working Life"}

\section{Feelings about preparedness for work}

"Everybody used to be completely stressed; I remember one of the lads who used to break out in a sweat before he would think of putting in a cannula."

(Interview 6, female, traditional entry, early twenties)

All of the interns interviewed spoke of having a good idea of how the clinical skills tasks are completed or how the equipment is put together, but "live" performance is 
very different to "simulation" and is seen initially as stressful and nerve wrecking. All interns feel that the first three weeks or so are a steep learning curve and confidence then grows once you begin to gain competence. There were no direct patient safety concerns expressed to me apart from some delays in placing night time cannulae or bruising patients through multiple failed "blood-taking" attempts.

Simulation and its role in preparedness

"(Simulation drills on clinical skills) ... it was a useful platform, but regards with trying to turn it towards reality, there is no comparison you know."

(Interview 3, male, traditional entry, early twenties)

There are clear views that simulation drills are useful. Graduate doctors speak about the usefulness of knowing the protocol steps for the doing of a procedure. They also like getting to know the equipment needed for skills tasks. Some favour multiple practice sessions and getting as close to perfection as possible, before embarking on procedural clinical skills with a "live" patient. Others see this simulation practice as unnecessary, and feel students should regularly practice on "live" patients in a supervised setting, once the basics are known. The "Simulation Man" (talking and moving robot) drills done as a student and pre starting work were noted to be particularly useful, as the scenarios here were widened to the management of sick patients on call.

Intravenous medication minefields whilst at work

"I started in hospital so there was an onus on you to kind of do first doses (Intravenous Antibiotics), I mean Jesus like I was making up stuff there that I shouldn't have been making up like, you know, and it was just like, you know 'You' re the doctor you have to do it' without ever been shown how to put it (the drug), into normal saline."

(Interview 2, male, graduate entry, late twenties)

The administering of Intravenous drug and fluid treatments cause a lot of wardbased stress for interns. There is pre-work training in this area, and all the wards have manuals and advice and protocol sheets, but it still is not enough. There is still a requirement for interns to give all 'first doses' of any newly prescribed intravenous treatment. These are remnants of historical hospital protocols, which have not changed in some Irish hospitals. This system is abolished in many hospitals but adds significantly to the stress of a night on call for many new intern graduates. Dosing in most other paramedical specialities is double checked also, but interns act alone, unless they seek a, medical or nursing colleague to help them. Some interns spoke of minor dosing errors but none that compromised patient safety. Intravenous pump systems for more longitudinal drug-dosing over hours and being asked to take blood from central based lines or peripheral blood lines or even remove these type lines from patients when they are no longer useful, is a worry for some graduate doctors. There is a paucity of training here.

Suturing skills: a deficit

"I would love to be able to confidently suture and I definitely wouldn't be confident doing that today. It's something that I will practice a lot more on before I start as an SHO. It was one of the skills when I started the degree that I thought I would have un- 
der the belt by now but it's not."

(Interview 1, male, traditional entry, early twenties)

There are many concerns expressed about the lack of training in suturing. It seems to be only available as a special study module. Interns in "Obstetric Medicine" need these skills immediately upon starting work in the labour ward and opportunities for teaching and training can also be lost to interns if consultant bosses see they cannot suture in theatre or during a ward based procedure.

Leaps from theory to practice (transitions)

"I suppose like I mean everything's going to be different in practice when you actually go and actually do the thing, it's going to be more scary and more real. And I suppose nothing can really prepare you for it."

(Interview 8, male, traditional entry, early twenties)

The newly graduated doctors also were totally unaware of the amount time spent by interns preparing for ward rounds. Interns soon realised that the correct X-rays, letters, blood results and test results were their personal responsibility and they needed to have these ready each morning for the senior doctors. This was an unexpected administration job for many.

Clerkships and whether they help with competence/transitions

"Some of the teams in the hospital accept students more than others but I think if they knew that they could actually participate, do odd jobs, you know, simple things like bloods, a lot of other teams might open up and be more willing to involve student learners. I think the big area is just trying to get the students to participate or get them more involved in the clinical setting rather than as passive observers, fly on the wall sort of syndrome."

(Interview 1, male, traditional entry, early twenties)

The overwhelming response here is that the clinical clerkship experience is largely passive, with a small few exceptions. On reflecting back to their clinical clerkship experiences graduates feel that bedside teaching for students is haphazard on ward rounds and never guaranteed. The dilemma is whether students in the final years of medical training are willing to play dice on whether a ward round will give worthwhile educational opportunities or not.

Most can see the benefits of being directly involved with a team and getting the chance to help with administration duties and at least see some ward based procedural skills, some do not and feel all this can be learned when on the job. Students are keen to have responsibilities with teams and can see the benefits this type of close contact can have for their future working life.

\subsection{Overarching Theme 5.0: "Personal Factors at Play in Preparedness for Work"}

The skills in developing/using networks for help

"I would have had a lot of friends in the year ahead, so they would have kind of let me do stuff whereas a lot of people would have been nervous enough if you didn't know 
somebody." (Interview 5, male, traditional entry, mid twenties)

Those who have "friends" working as doctors or well established networks in the medical ranks on the ward get more access to "hands-on" teaching and practice. If you don't know anybody, it can be quite uncomfortable to ask for learning opportunities from working practitioners. There is also a strong feeling that having an established network of friends amongst those already working means the job description of the intern is well known prior to commencement of employment. These friendship and support networks, if in existence, continue to function at work, and interns gain easier access to clinical support and gain mentorship advice through these networks and also of course easier access to "consults".

Personality and preparedness

"Well for me anyway, like $1 \mathrm{~m}$ terrible with, that was one of my weakest attributes, would be multi-tasking, and trying to, one source of information at a time is all I can deal with, and even after a year of internship, that's still all I can do."

(Interview 9, female, traditional entry, mid twenties)

The ability to multi-task is vital for effective ward work. The interns though are unsure how a university could prepare you for this.

Personality traits may be difficult to change. A lack of ability to participate in team work, or the failure to complete job tasks are issues that interns remark upon seeing in some peers. It's often easy for others to pick up the slack from a poorly performing colleague and for unprofessional behaviour to go unnoticed by supervisors.

Interns feel that an individual's personality can play a huge role in the chance to practice advanced clinical skills tasks in supervised environments. The more cavalier type student will get more opportunities as they can be fearless at trying out first time tasks on patients. Those who are naturally over cautious may not get these type teaching and learning chances on wards and are much more reluctant to volunteer.

The approach taken to challenges when transitioning from student to doctor

"To be honest now I went in at the deep end I haven't done any preparation at all. I suppose it's like any job I just approach, like, you know, you just put yourself in the deep end and within two or three weeks you are ok, you know, you just have to, you know, I wasn't prepared at all like to be honest for the practical things. I don't think I had even done one properly like."

(Interview 1, male, graduate entry, late twenties)

Some interns felt that the intern job is like any other job, and "on the job" training is a standard occurrence. These doctors felt that total immersion into work, leads to the development of competence over a small number of weeks, during which they would be supported by senior medical staff or colleagues. These interns did not see any patient safety concerns with this. Other interns felt that their own cautious nature would not allow them to settle for workplace training alone. These intern doctors would have done a lot of preparatory work before starting work. A number also speak about the problems associated with being over cautious. Interns like this can lack the ability to make definite decisions and thus easily move onto the next job task. They do however 
seek help easily and thus avoid potential patient safety issues. Many interns stressed the importance of teamwork between the entire intern cohort at work and helping each other.

\section{Discussion}

Despite the many curricular changes in the last ten years, in both the undergraduate and postgraduate courses, the transition from medical school to clinical practice is far from ideal and quite stressful for intern doctors starting work.

Overall the intern cohort seemed largely unsure whether they were prepared for work or not. The idea of what "prepared for work" means is under-explored in the literature and very little is provided by means of a way to measure what this is anyway [5]. Other research suggests that neither the interns themselves nor their supervisors are any good at assessing competence levels in the first place [6]. There must also be questions about whether or not any value can be found in short term, "right here, right now" type questionnaires that dominate the literature. In these type questionnaires, social cognitive processes have often shown that responders manifest a "better than average effect", where the majority of people believe themselves, maybe as a self-esteem protective mechanism, to be better at most things than average.

Interns have issues with time management and job prioritisation after graduation from the medical school. These findings had already been confirmed by previous research [7]-[10]. The need for an appropriate shadowing experience was discussed in the literature also [11]. It is suggested that the shadowing experiences of doctors can help with time management skills. Information technology type tasks are learned on the job and stressful initially, but they are soon learned. Clinical supervisors agree with this [13]. It is clear that more of the so called softer skills such as multi-tasking, knowing when to seek help, workload management, dealing with others in a poly-professional team need to be acquired earlier by doctors [12]. These can certainly be acquired through a more participatory type student clinical clerkship [5].

Consent, resuscitation, ethics on the frontline and patient safety issues and other such "real-world issues" are a constant source of stress for the intern group. The period of transition from student to doctor can be viewed as a critical intensive learning period [12] and the success of any transition can be dependent on the context of the workplace setting and the depth of supportive interpersonal and supervisory levels available. Whether the issue takes place at night or day or in a familiar workplace setting or not is also vital. The reality is that preparedness for these "real world issues" is often seen as piecemeal but superior levels of support, supervision and socialisation to the various clinical settings along with a well-practiced skill set improves things for junior doctors during these periods [7] [9] [10]. Hannon [7] further found that the management of patient autonomy and consent issues were inadequate when interns were starting out at work, but improved greatly over the year. This was in contrast to their findings about the ethics of death and dying which suggested the interns were often more confused after completing their intern year. 
Preparedness for ethical dilemmas has been all too often omitted from many of the published work on this subject matter and is oftentimes not listed as a competence needed for internship. Tallentire et al. [13] and Lempp et al. [14] felt that their graduates were adequately trained for ethical and legal decision making. This is at odds with some other published work most notably [7] [8] who found that separate cohorts of their interns felt poorly prepared for these type scenarios. Of note, the PBL course introduced in Manchester [8] seemed to improve the ethical thinking of the group. The way we teach ethics and the usefulness of this, was examined by McDougall [15], who felt that case based discussions on ethical dilemmas are fine but doctors at the coal face need skills to implement their ethical ideas in "real-life" to help make good decisions. This sentiment can be echoed by the graduate cohort in my study. Ethical teaching seems more useful and needs to be placed in the clinical years as opposed to pre-clinical professionalism modules as it is currently in many universities [16].

A meta-analysis on simulation says that simulation and deliberate practice is better than traditional clinical education, in performing clinical skills [17]. This finding is in contradiction of the intern's views. They believed that time gaps between simulation lessons and "real life" practice opportunities are at the root of poor preparedness for these clinical skills tasks when starting work. They also believe that the leap from theory to practice in clinical skills is significant, which was a similar finding to Kavanagh et al. [18]. A lack of preparedness in suturing skills is frequently mentioned similar to Jones et al. [8] It may however be adequate for clinical skills to be learned "on the job" [9] [10].

Being on call and becoming the first responder to ward based medical emergencies is a stressful task for intern doctors. They feel poorly prepared for this and spend enormous effort and energy trying to get up to speed with the many required skills during the first weeks and months [7] [9] [10]. Lucey [19] has opposing views and feel graduates were maybe over exposed to acute care scenarios but not getting enough poly professional workplace training. Context however is critically important as it is accepted that doctors can perform better when the challenge occurs in a context they know well (i.e. day time, on their own ward) [12].

Most interns here rated their history taking and communication skills as being of strength when starting work [9] [13] [20]. Wall et al. [20] questioned whether competence in the communication domain was a result of extended teaching in this field and if so, was it at the expense of more real world teaching (script writing, emergency management, drugs etc.)

More complex communication tasks were still seen as a difficulty in Nottingham [21]. Relationships are crucial in working environments. Nursing colleagues can be a source of help or stress. Interns may struggle with the complexities of dealing with confrontation, ensuring care orders are done and explaining care decisions during the rigorous demands of being on-call. This issue was discussed in great detail by Lempp et al. [14], and echo many of the findings reported above. Notably, Hannon [7] found that two thirds of the intern cohort when they commenced work had a poor understanding 
of the contribution of other healthcare workers. There are theoretical frameworks based on workplace transitions which show that unless there is a clear socialisation process in place with work colleagues and superiors, transitions and progress for junior doctors is slower [5] [12]. This perhaps must be built into more curricula for undergraduates?

Most of the graduates feel help is available when asked for [20] [22]. There was little discussion in the literature about the stress of seeking "consults" or "getting consents" from pre-operative patients, when procedures are not fully understood. These are a huge workload for Irish interns and perhaps reflect differing national health systems or approaches to healthcare. Surgical teams were seen as less supportive and interns worked oftentimes alone on surgical rotations [23].

The intravenous workload that some interns have to perform is a worry for them. There is little preparedness for this role apart from some work in the intern shadowing period. There is little mention of this task in the literature because this is perhaps a "nursing lead" job in the U.K and U.S.A. In Ireland, it is still largely the role of the intern to make up first dose intravenous medication and administer these. There are clear patient safety implications here as the intern group feels poorly prepared for this but it's easier to succeed with any task when in a familiar workplace context that's known to them [5] [12].

There is no doubt that active clinical clerkships can help prepare graduates for work. This sentiment is clearly illustrated by many including the GMC Education Committee Report 2008 [9] [22]. Some students however are wary of wasting potential study time following clinical teams, when this activity is frequently unproductive. Some of the intern group are perhaps unaware of the need to socialise in order to succeed in the medical world [24]. The development of Bourdieu's concept of "habitus" can really only be achieved by taking one's place in "the field" (medical working environment). This needs perhaps to be more explicitly stated to all undergraduates, especially those who seem unaware of this.

From earlier work it is already established that neuroticism was associated with poor preparedness for work whilst conscientiousness and extraversion were correlated with preparedness [25]. It is also postulated that fear of transitions can have a much larger impact on performance after a transition to the workplace from collage than was previously thought [26]. Our cohort noted that introversion can also be a barrier to making effective decisions. Furthermore, you can also lose out on the possibilities to "step up "and perform a supervised task beyond your known skill set, if you are fearful to volunteer. Seligman [27] also believed that many personal aspects affect performance at work. Notably he believed that long standing fears or indeed attitudes to these can affect performance and degrees of preparedness.

Having a network of friends is often a vital support in times of difficulty. Many interns spoke of how having a "doctor" friend in the years ahead of them helped with feeling prepared for work enormously. Cave et al. [25] also showed that having role models during your training was correlated well with preparedness for work. Draper \& Louw [28] also found that those who had high levels of personal initiative were more 
prepared for work. This sentiment was also shared by these interns. This desire to have a wide social network ties very much the theory of Bourdieu when applied to the "socialisation of medicine" and by Balmer et al. [29]. Young doctors need to internalise particular dispositions (such as flexibility and initiative) and various rules and preferences from the working medical environment or field, and this allows the individual to construct one's own identity.

There are a number of limitations to this study. First, the absolute number of interview was low and it is also hard to generalise results from one setting at one particular time. That being said my findings are akin to the common themes emerging in the literature in this area.

\section{Conclusion}

A study based on how newly qualified doctors view their degree of preparedness for work is valuable. The literature is largely based on cross sectional survey data. The ability to expand a study to include interviews/focus groups makes for richer data and allows the researcher to explore the deeper meanings to any of the expressed opinions. The study has established that the medical school in which the study was situated is teaching its graduates to an acceptable standard with regard to their medical knowledge base, communication skill abilities and the basic tenets of history taking and examination, but it needs to prepare graduates in a more concrete way for working in complex multi-professional clinical environments and for participating effectively in the context of acute medical emergencies. It is arguable that all medical schools should follow up their graduates to assess how well the medical school curriculum has prepared their graduates for practice and make appropriate changes where necessary.

\section{References}

[1] Hurwitz, B. and Vaas, A. (2002) What's a Good Doctor, and How Can You Make One? BMJ, 325, 667-668. http://dx.doi.org/10.1136/bmj.325.7366.667

[2] General Medical Council (UK) (2009) Tomorrow's Doctors. London. http://www.gmc-uk.org/Tomorrow_s_Doctors_1214.pdf_48905759.pdf

[3] Kennedy, T.J. and Lingrad, L.A. (2006) Making Sense of Grounded Theory in Medical Education. Medical Education, 40, 101-108. http://dx.doi.org/10.1111/j.1365-2929.2005.02378.x

[4] Gibbs, G. (2007) Analysing Qualitative Data. SAGE Publications Ltd., New York, USA. http://dx.doi.org/10.4135/9781849208574

[5] Monrouxe, L., Bullock, A., Cole, J., Gormley, G., Kaufhold, K., Kelly, N., et al. (2014) How Prepared Are UK Medical Graduates for Practice? GMC.

[6] Fox, R.A., Ingham Clark, C.L., Scotland, A.D. and Dacre, J.E. (2000) A Study of Pre-Registration House Officer's Clinical Skills. Medical Education, 34, 1007-1012. http://dx.doi.org/10.1046/j.1365-2923.2000.00729.x

[7] Hannon, F.B. (2000) A National Medical Education Needs' Assessment of Interns and the Development of an Intern Education and Training Programme. Medical Education, 34, 275-284. http://dx.doi.org/10.1046/j.1365-2923.2000.00512.x 
[8] Jones, A., McArdle, P.J. and O Neill, P.A. (2002) Perceptions of How Well Graduates Are Prepared for the Role of Registration House Officer: A Comparison of Outcomes from a Traditional and an Integrated P.B.L Curriculum. Medical Education, 36, 16-25. http://dx.doi.org/10.1046/j.1365-2923.2002.01105.x

[9] GMC Education Committee Report 2008: How Prepared Are Medical Graduates to Begin Practice? A Comparison of Three Diverse UK Medical Schools.

http://www.gmc-uk.org/FINAL_How_prepared_are_medical_graduates_to_begin_practice September_08.pdf_29697834.pdf

[10] Illing, J.C., Morrow, G.M., Rothwell nee Kergon, C.R., et al. (2013) Perceptions of UK Medical Graduates' Preparedness for Practice: A Multi-Centre Qualitative Study Reflecting the Importance of Learning on the Job. BMC Medical Education, 13, 34. http://dx.doi.org/10.1186/1472-6920-13-34

[11] Matheson, C., Matheson, D., Saunders, J.H. and Howarth, C. (2010) The Views of Doctors in Their First Year of Medical Practice on the Lasting Impact of a Preparation for House Officer Course They Undertook as Final Year Medical Students. BMC Medical Education, 10, 48. http://dx.doi.org/10.1186/1472-6920-10-48

[12] Kilminster, S., Zukas, M., Quinton, N. and Roberts, T. (2011) Preparedness Is Not Enough: Understanding Transitions as Critically Intensive Learning Periods. Medical Education, 45, 1006-1015. http://dx.doi.org/10.1111/j.1365-2923.2011.04048.x

[13] Tallentire, V.R., Smith, S.E., Wylde, K. and Cameron, H.S. (2011) Are Medical Graduates Ready to Face the Challenges of Foundation Training? Postgraduate Medical Journal, 87, 590-595. http://dx.doi.org/10.1136/pgmj.2010.115659

[14] Lempp, M., Seabrook, M., Cochrane, J.R. and Rees, J. (2005) The Transition from Medical Student to Doctor: Perceptions of the Final Year Students and Pre-Registration HouseOfficers Related to Expected Learning Outcomes. International Journal of Clinical Practice, 59, 324-329. http://dx.doi.org/10.1111/j.1742-1241.2005.00438.x

[15] McDougall, R. (2009) Combating Junior Doctors “4AM Logic": A Challenge for Medical Ethics Education. Journal of Medical Ethics, 35, 203-206. http://dx.doi.org/10.1136/jme.2008.026609

[16] Forrow, L., Arnold, R.M. and Frader, J. (1991) Teaching Clinical Ethics in the Residency: Preparing Competent Professionals. Journal of Medicine and Philosophy, 16, 93-112. http://dx.doi.org/10.1093/jmp/16.1.93

[17] McGaghie, W.C., Barry Issenberg, S., Cohen, E.R., Barsuk, J.H. and Wayne, D.B. (2011) Does Simulation Based Medical Education with Deliberate Practice Yield Better Results Than Traditional Clinical Education? A Meta-Analytic Comparative Review of the Evidence. Academic Medicine, 86, 706-711. http://dx.doi.org/10.1097/ACM.0b013e318217e119

[18] Kavanagh, P., Boohan, M., Savage, M., Mc Cluskey, D., et al. (2012) Evaluation of a Final Year Work-Shadowing Attachment. Ulster Medical Journal, 81, 83-88.

[19] Lucey, C.R. (2013) Medical Education: Part of the Problem and Part of the Solution. JAMA Internal Medicine, 173, 1639-1643. http://dx.doi.org/10.1001/jamainternmed.2013.9074

[20] Wall, D., Boshaw, A. and Carolan, J. (2006) From Undergraduate Medical Education to Pre-Registration House Officer Year: How Prepared Are Students? Medical Teacher, 28, 435-439. http://dx.doi.org/10.1080/01421590600625171

[21] Matheson, D. and Matheson, C. (2009) How Well Prepared Are Medical Students for Their First Year as Doctors? The Views of Consultants and Specialist Registrars in Two Teaching Hospitals. Postgraduate Medical Journal, 85, 582-589. http://dx.doi.org/10.1136/pgmj.2008.071639 
[22] Brennan, N., Corrigan, O., Allard, J., Archer, J., et al. (2010) The Transition from Medical Student to Junior Doctor: Today's Experience of Tomorrow's Doctors. Medical Education, 44, 449-458. http://dx.doi.org/10.1111/j.1365-2923.2009.03604.x

[23] Goldacre, M.J., Lambert, T., Evans, J. and Turner, G. (2003) Pre-Registration House Officers Views on Whether Their Experience at Medical School Prepared Them Well for Their Jobs: National Questionnaire Survey. BMJ, 326, 1011-1012.

http://dx.doi.org/10.1136/bmj.326.7397.1011

[24] Luke, H. (2003) Medical Education and Sociology of Medical Habitus: "It's Not about the Stethoscope!" Kluwer Academic Publishers, Dordrecht, Netherlands.

[25] Cave, J., Woolf, K., Jones, A. and Dacre, J. (2009) Easing the Transition from Students to Doctor; How Can Medical Schools Help Prepare Their Graduates for Starting Work. Medical Teacher, 31, 403-408. http://dx.doi.org/10.1080/01421590802348127

[26] Schlossberg, N.K. (1984) Counselling Adults in Transition: Linking Practice with Theory. Springer Publishing Company, Inc., New York.

[27] Seligman, M.E.P. (1971) Phobias and Preparedness. Behaviour Therapy, 2, 307-321. http://dx.doi.org/10.1016/S0005-7894(71)80064-3

[28] Draper, C.E. and Louw, G.J. (2012) Competence for Internship: Perceptions of Final-Year Medical Students. Education for Health: Change in Training and Practice, 25, 16-23. http://dx.doi.org/10.4103/1357-6283.99202

[29] Balmer, D.F., Richards, B.F. and Varpio, L. (2015) How Students Experience and Navigate Transitions in Undergraduate Medical Education: An Application of Bourdieus Theoretical Model. Advances in Health Sciences Education: Theory and Practice, 20, 1073-1085. http://dx.doi.org/10.1007/s10459-015-9588-y 


\section{Appendix}

Table A1. Details of interviewees.

\begin{tabular}{|c|c|c|c|}
\hline $\begin{array}{l}\text { Interview } \\
\text { number }\end{array}$ & Sampling & Age/Background & $\begin{array}{l}\text { Date/Length of } \\
\text { time }\end{array}$ \\
\hline 1 Male & (Random) Response to text message & $\begin{array}{l}\text { Mid twenties/(UG) } \\
\text { Undergraduate when } \\
\text { started medical school }\end{array}$ & $10 / 6 / 14,27 \mathrm{mins}$ \\
\hline 2 Male & $\begin{array}{l}\text { Purposeful sampling } \\
\text { (Postgraduate intern) }\end{array}$ & $\begin{array}{c}\text { Late twenties/(PG) } \\
\text { Postgraduate when } \\
\text { started medical school }\end{array}$ & $13 / 6 / 14,29 \mathrm{mins}$ \\
\hline 3 Male & (Random) Response to text message & Mid twenties/(UG) & $13 / 6 / 14,17$ mins \\
\hline 4 Male & (Random) Response to text message & Mid twenties/(UG) & $13 / 6 / 14,20 \mathrm{mins}$ \\
\hline 5 Male & $\begin{array}{c}\text { Purposeful sampling } \\
\text { (Peripheral hospital intern) }\end{array}$ & Mid twenties/(UG) & $27 / 6 / 14,26 \mathrm{mins}$ \\
\hline 6 Female & $\begin{array}{c}\text { Purposeful sampling } \\
\text { (Peripheral hospital intern) }\end{array}$ & Mid twenties/(UG) & $1 / 7 / 14,25$ mins \\
\hline 7 Male & "Snowball effect" heard via friend & Mid twenties/(UG) & $1 / 7 / 14,25$ mins \\
\hline 8 Female & "Snowball effect" heard via friend & Mid twenties/(UG) & $2 / 7 / 14,27 \mathrm{mins}$ \\
\hline 9 Male & (Random) Response to text message & Mid twenties/(UG) & $3 / 7 / 14,25$ mins \\
\hline 10 Female & Purposeful sampling ( Primary care intern) & Mid twenties/(UG) & $3 / 7 / 14,30$ mins \\
\hline
\end{tabular}

Table A2. Semi-structured interview guide (highlight examples and how competencies affect work).

1) Were you fit for purpose when you started work?

2) What were the big issues, where you felt unprepared for work?

3) Can you tell me about any specific ethical issues that cropped up for you as an intern? Probe into patient consent issues/Resuscitation, end of life issues/legal issues

4) Did you ever feel out of your depth with time management or job prioritisation issues? Ask re Bleep systems issues/On-call

5) Do you know your limits (management, clinical skills)?/On-call

6) How did you find the work environment? If complex how so? Probe Nursing and others

7) How were your I.T skills? Probe into administration tasks, typing skills, Radiology/lab systems

8) How did you manage with your clinical ward skills (examples taking blood, ABG, IV lines, Urinary catheters, N/G tubes etc.). Ask about suturing?

9) Did you ever feel out of your depth with these clinical ward skills

10) Can I ask about how you feel about your IV drug skills (prescribing, putting together, giving doses)? 
Table A3. Table of themes, sub-themes and definitions.

\begin{tabular}{|c|c|c|c|}
\hline Overarching Themes & Subthemes & $\begin{array}{l}\text { Description of } \\
\text { Subthemes }\end{array}$ & Quotes \\
\hline \multirow[t]{4}{*}{$\begin{array}{l}\text { 1.0: Real world issues } \\
\text { for the student } \\
\text { transitioning to doctor }\end{array}$} & $\begin{array}{l}\text { 1.1: Procedural } \\
\text { and patient } \\
\text { consent dilemmas }\end{array}$ & $\begin{array}{l}\text { The clinical skills } \\
\text { tasks that a junior } \\
\text { doctor commonly } \\
\text { does at the patient's } \\
\text { bedside and consent } \\
\text { for these }\end{array}$ & $\begin{array}{l}\text { "I started off as I say in surgery and } \\
\text { wouldn't even have half a clue what } \\
\text { the procedures were like." } \\
\text { (Interview } 5, \text { Male, mid-twenties) }\end{array}$ \\
\hline & $\begin{array}{l}\text { 1.2: Competence } \\
\text { in resuscitation }\end{array}$ & $\begin{array}{l}\text { The activity that takes } \\
\text { place after a cardiac } \\
\text { arrest }\end{array}$ & $\begin{array}{l}\text { "You know the steps that were taken, } \\
\text { you know, in the ACLS algorithm, } \\
\text { but I was never involved in any } \\
\text { decision making myself, you know, } \\
\text { you try and get your line in ..." } \\
\text { (Interview } 7, \text { Male, mid-twenties) }\end{array}$ \\
\hline & $\begin{array}{l}\text { 1.3: Ethics from } \\
\text { the frontline as a } \\
\text { new doctor }\end{array}$ & $\begin{array}{l}\text { Decision making and } \\
\text { how these decisions } \\
\text { are made form a new } \\
\text { doctors viewpoint }\end{array}$ & $\begin{array}{l}\text { "We actually had one night where we } \\
\text { had two arrests here at the same time, } \\
\text { in two rooms next to each other, and } \\
\text { then that was a total (pause) ... there } \\
\text { are a lot of people... where you are } \\
\text { probably putting through a lot of, you } \\
\text { know, people that really shouldn't be } \\
\text { resuscitated." } \\
\text { (Interview } 5, \text { Male, mid-twenties) }\end{array}$ \\
\hline & $\begin{array}{l}\text { 1.4: Patient safety } \\
\text { and preparedness } \\
\text { for work }\end{array}$ & $\begin{array}{l}\text { The levels of } \\
\text { preparedness that } \\
\text { doctors feel they have } \\
\text { in dealing with } \\
\text { patients safely }\end{array}$ & $\begin{array}{l}\text { "(Clinical Skills task) People get } \\
\text { frustrated and the more frustrated } \\
\text { people get, the more panicky you get, } \\
\text { then the whole things a disaster, } \\
\text { where in truth, it could be someone } \\
\text { fairly sick". } \\
\text { (Interview } 9, \text { Male, mid-twenties) }\end{array}$ \\
\hline \multirow[t]{2}{*}{$\begin{array}{l}\text { 2.0: Ward Life and how } \\
\text { it impacts on } \\
\text { performance }\end{array}$} & $\begin{array}{l}\text { 2.1: Practicalities } \\
\text { of ward life }\end{array}$ & $\begin{array}{l}\text { The day to day office } \\
\text { and administration of } \\
\text { a ward/hospital }\end{array}$ & $\begin{array}{l}\text { "Other things are like logistical } \\
\text { things... like ordering stuff. The fact } \\
\text { that as an intern you very much a } \\
\text { paper pusher and organiser and I } \\
\text { think if you' re not determined to get } \\
\text { something done yourself, then a lot of } \\
\text { the jobs can be left or pushed back } \\
\text { and I think that can affect the overall } \\
\text { working of the whole hospital." } \\
\text { (Interview } 8, \text { Female, mid-twenties) }\end{array}$ \\
\hline & $\begin{array}{l}\text { 2.2: After dark } \\
\text { (on-call) }\end{array}$ & $\begin{array}{l}\text { The period of time } \\
\text { after } 6 \text { PM until } \\
\text { morning when the } \\
\text { hospital runs on a } \\
\text { skeleton staff and } \\
\text { junior staff are much } \\
\text { more exposed to } \\
\text { clinical care scenarios }\end{array}$ & $\begin{array}{l}\text { "Sometimes it really clear, I remember } \\
\text { getting a phone call on a bad call, two } \\
\text { patients with early warning scores of } \\
\text { seven and one patient who was } \\
\text { confused with a blood sugar of one, } \\
\text { so you can automatically go, oh well } \\
\text { this decision is made for me here, but } \\
\text { other times when you run around, } \\
\text { and you are like kind of oh, and when } \\
\text { you are really busy it can be difficult } \\
\text { to decide." } \\
\text { (Interview } 6, \text { Female, mid-twenties) }\end{array}$ \\
\hline
\end{tabular}




\section{Continued}

3.0: Professional relationships and their impact on preparedness for work and performance
3.1: Nursing colleagues and how relationships impact on performance
3.2: Medical seniors and their roles
Support from Medical Consultants and Registrars who are their deputies
Nursing staff and the impact of this relationship on work for junior doctors
3.3: Skills for acquiring cross-team consultations
4.0: Skills Deficits in the working life preparedness for work

4.2: Simulation and its role in preparedness

4.3: Intravenous medication minefields whilst at work

4.4: Suturing skills: a training deficit ask a junior team member to get another but different specialities team to visit a sick patient This usually involves calling the different specialities registrar (second in command).

How junior doctors feel about their ability to do their job from their university or hospital based training

Simulation is performing a clinical skill on a mannequin or actor

Intravenous medicines are medicines given directly into a vein and thus much more complex than oral tablets

This describes the experience of stitching a wound
"If you got 4000 calls at one time you would be stressing out, the nurses might tell you the thing to do, but the thing might not be needed until twelve o clock, the nurses wouldn't tell you that, they just want their own patients looked after."

(Interview 4, Male, mid-twenties)

"(Support) I think it kind of depends, I suppose I started off in surgery and you don't really have much interaction with the surgical senior house officer on the wards. You don't really have much interaction with anyone on the surgical wards; you just plod along and kind of do your own thing."

(Interview 5, Male, mid-twenties)

"Horrific, I used to avoid it if I could, so I would make deals with other team members, like I ll do the blood forms if you do the consults. Like some of the Reg's are like horrible to you on the phone especially if you are the intern."

(Interview 10, Female, mid-twenties)

"I was very nervous, and I think that's kind of a general feeling among everyone, and I think that's just because of the huge like responsibility in caring for people's lives." (Interview 8, Female, mid-twenties)

"They are hugely beneficial when you are starting out for the first time. I suppose it will always be good to practice these on patients after a sufficient amount of time." (Interview 7, Male, mid-twenties)

"I found myself holding bits of equipment trying to think which part goes where, I draw this from here and then I dilute it with this, it's a very messy slow and laborious procedure ... it still takes me a lot of time to do."

(Interview 1, Male, mid-twenties)

"I haven't been asked or haven' $t$ needed to suture but it is something I would like to do."

(Interview 1, Male, mid-twenties) 


\section{Continued}

4.0: Skills Deficits in the 4.5: Leaps from working life

0: Personal Factors in preparedness for work with compet tions

5.1: Attitude to theory to practice (transitions)
This examines the transitioning from the university to the workplace

4.6:Clerkships and whether they help work as a student and how it impacts on preparedness for work

5.2: The skills in developing/using networks for help people in whom the student/junior doctor feels socially accepted

Clerkships are perio on training that is "hands on" in the i workplace environment and takes place when the junior doctor is a university student

This explores attitudes (1)

5.3: Personality and preparedness

This explores the personality of students/junior doctors

5.4: The approach taken to challenges when transitioning from student to doctor
"Like you learn all the theory but you don't know how to put that into practice."

(Interview 6, Female, mid-twenties)

"When you came on board, agh, it was like you were a kind of hindrance to the team, your kind of causing them delays, asking them questions and stuff.'

(Interview 3, Male, mid-twenties)

"( Final Med) I think you are better off to focus on learning the medicine."

(Interview 10, Female, mid-twenties)

"It would be way more daunting, I think it really helps if you have somebody who is going to, you know, give you a hand or give you a heads up."

(Interview 6, Female, mid-twenties)

"I Think there's a mix of interpersonal skills needed (being an intern/ doctor) ... initiative and personal responsibility, and I think those kind of factors are not really taught in medical school at all." (Interview 8, Female, mid-twenties)

“I wouldn' $t$ call it overwhelming, but it (the workload) does feel like a lot to do just from a sheer volume point of view, so how can you improve on that ..., it s just you adapt and you improve."

(Interview 1, Male, mid-twenties) 
Submit or recommend next manuscript to OALib Journal and we will provide best service for you:

- Publication frequency: Monthly

- 9 subject areas of science, technology and medicine

- Fair and rigorous peer-review system

- Fast publication process

- Article promotion in various social networking sites (LinkedIn, Facebook, Twitter, etc.)

- Maximum dissemination of your research work

Submit Your Paper Online: Click Here to Submit

Or Contact service@oalib.com 